\title{
Value of ST- Segment Depression with T-Wave Inversion in Lateral Leads I, aVL, V4-V6 in Diagnosing the Left Main or Left Main Equivalent Coronary Artery Disease
}

\author{
Sambhu Kumar Mallick, Mahboob Ali, Amal Kumar Chowdhury \\ Department of Cardiology, National Institute of Cardiovascular Disease, Dhaka.
}

\begin{abstract}
:
Keywords:

Background: Critical stenosis in the proximal part of the left anterior descending, severe 3 vessel ECG, IHD, disease and left main stem stenosis have all been recognized as clinical conditions complicated by a high incidence of large infarction, pump failure, arrhythmias and sudden death in patients with Coronary artery, Left main acute coronary syndrome (ACS). As many effective treatment modes are available currently, early recognition of those circumstances is crucial for appropriate management.

coronary artery.

Methods: this observational study was carried out at the Department of Cardiology, National Institute of Cardiovascular Disease (NICVD), Dhaka. Patients (30 patients) with NSTEACS having $S T$-segment depression with T-wave inversion maximally in leads I,avL,V4-V6 were considered as cases (Group I) and those (30 patients) with ST-segment depression without T-wave inversion in lateral leads were controls (Group II). Coronary angiogram (CAG) was done during in-hospital stay.

Results: In present study, it was evident that among group I patients, 43.3\% had stenotic lesion in left main artery (LM) and $26.67 \%$ in LM equivalent coronary artery (LME CA), whereas had no stenotic lesion in LM and 3.33\% had LME CA lesion in group II patients. Low cost, widely available ECG criteria is supposed to be useful predictor of left main or left main equivalent coronary artery obstruction (Sensitivity $=95 \%$, Specificity $=76 \%$, Positive predictive value $=70.0 \%$ and Negative predictive value $=97.0 \%)$ and high $S T$-segment changes score (>18 $\mathrm{mm}(100 \%)$ \&/or ${ }^{3} 10 \mathrm{~mm}(80 \%)$ was an additive predictor of LM or LMECA lesion.

Conclusion: Maximum ST- segment depression with T-wave inversion in the lateral leads I, aVL, V4-V6 on admission ECG can predict the critical LM or LMECA obstruction in patients with NSTEACS. It can help to provide prompt and appropriate management earlier to reduce the mortality \& morbidity.
\end{abstract}

(Cardiovasc. j. 2017; 9(2): 135-141)

\section{Introduction:}

Worldwide, Coronary heart disease (CHD), the most common cardiovascular disease, is the single most frequent cause of death in middle-aged and older people in most of the developed and many of the developing countries. ${ }^{1}$

Presentation of ACS is different depending on the coronary artery involvement, severity, degree of collateral circulation and myocardial oxygen demand. Critical stenosis in the proximal part of the left anterior descending, severe 3 vessel disease and left main stem stenosis have all been recognized as clinical conditions complicated by a high incidence of large infarction, pump failure, arrhythmias and sudden death. Significant narrowing of the LM and LMECA disease i.e. proximal LAD and proximal LCX disease puts the patients at high risk, compromises flow to approximately 75 percent of the left ventricle. ${ }^{2} \mathrm{As}$ because many effective treatment modes are available currently, early recognition of those circumstances is crucial for appropriate management. ${ }^{3}$

Electrocardiography leads especially I, aVL, V4V6 can be very helpful and valuable in ACS in diagnosing the site of coronary artery obstruction. ST-segment depression with T-wave inversion maximally in $\mathrm{V} 4-\mathrm{V} 6$ is a predictor of LM or LME

Address of correspondence: Dr. Sambhu Kumar Mallick, Clinical \& interventional Cardiologist, CMPH, Chittagong, Bangladesh. Email- milestonectg@gmail.com 
coronary artery disease with sensitivity and specificity were $91 \%$ and $79 \%$ respectively, positive and negative predictive values were $91 \%$ and $92 \%$ respectively and have high in-hospital mortality. They are high-risk patients and require more revascularization. ${ }^{4}$

The simple, non-invasive, inexpensive, widespread available, bedside tool electrocardiogram can help us to diagnose such critical lesion help to perform procedure like CAG more safely by taking preprocedural precaution in probable critical situation and also help us earlier prediction and diagnosis of the deadly lesion in the LM or LMECA, so that we can be able to take prompt, appropriate treatment strategy (i.e. multiple drugs therapy and undergo urgent $\mathrm{CABG}$ or $\mathrm{PCI}$ as a prelude to revascularization if feasible) to reduce the mortality and estimating the prognosis in acute coronary syndrome.

\section{Methods:}

This observational study was carried out during the period of August 2004 to July 2005 at the Department of Cardiology, NICVD. Patients with Non ST elevation ACS (Unstable angina and Non ST elevation MI) admitted in NICVD were included in the study. Patients having ST-segment depression with T-wave inversion maximally in leads I, aVL, V4-V6 were included as Group I (total 30)and patients having ST-segment depression without $\mathrm{T}$-wave inversion in lateral leads were included as Group II (total 30).

Informed consent was taken from each patient or from the legal guardian of the patient included in the study. They were neither supported nor additionally burdened financially. Confidentiality was maintained accordingly. Baseline clinical data including clinical history, physical finding and laboratory tests of the patients were recorded in a preformed data sheet. Admission electrocardiogram was recorded and evaluated.

CAG was done during hospital stay, stenosis e" $50 \%$ in $\mathrm{LM}$ or $\geq 70 \%$ in LMECA was considered significant. All the standard views were taken with special attention to AP, LAO-caudal, and LAOcranial \& RAO-caudal views for meticulous identification of LM or LMECA lesion. The degree of coronary stenosis was calculated in the projection where the greatest narrowing can be observed. The evaluation of the degree of a coronary stenosis was related to the percentage reduction in the diameter of the vessel.

All the relevant data were collected in the form of a questionnaire. All the data were analyzed by using the SPSS. Mean values \pm standard deviation were calculated for continuous variables and absolute and relative frequencies were measured for discrete variables. The statistical significance of differences between groups was analyzed by chisquare test in discrete variables. Student's t-test was used to analyze the continuous variables. A value of $p<0.05$ was considered as significant

\section{Results:}

This prospective observational study was conducted in the National Institute of Cardiovascular Diseases (NICVD), Dhaka during the period of August 2004 to July 2005.

Among the studied patients, there were 44 male and 16 female with male female ratio $2.75: 1$. The mean age of the male patients was $50.8 \pm 10.0$ years ranging from 40 to 75 years and the mean age of the female patients was $52.8 \pm 9.5$ years ranging from 27 to 75 years (Table-I).

Table-I

Distribution of the study patients by age and $\operatorname{sex}(n=60)$.

\begin{tabular}{|c|c|c|c|c|c|c|c|}
\hline \multirow[t]{2}{*}{ Age in Years } & \multicolumn{2}{|c|}{ Male } & \multicolumn{2}{|c|}{ Female } & \multicolumn{2}{|c|}{ Total } & \multirow[t]{2}{*}{$\mathrm{p}$ value } \\
\hline & No. & $\%$ & No. & $\%$ & No. & $\%$ & \\
\hline$<45$ & 9 & 20.5 & 2 & 12.5 & 11 & 18.3 & \\
\hline $45-54$ & 20 & 45.5 & 7 & 43.8 & 27 & 45.0 & \\
\hline $55-64$ & 11 & 25.0 & 5 & 31.2 & 16 & 26.7 & \\
\hline${ }^{3} 65$ & 4 & 9.0 & 2 & 12.5 & 6 & 10.0 & \\
\hline Total & 44 & 100.0 & 16 & 100.0 & 60 & 100.0 & \\
\hline Mean $\pm \mathrm{SD}$ (Range) & \multicolumn{2}{|c|}{$50.8 \pm 10.0(40-75)$} & \multicolumn{2}{|c|}{$52.0 \pm 9.5(27-75)$} & \multicolumn{2}{|c|}{$51.1 \pm 9.8(27-75)$} & $0.678^{\mathrm{NS}}$ \\
\hline
\end{tabular}

$\mathrm{p}$ value reached from unpaired student's t-test

Figure in parenthesis indicate range, $\mathrm{NS}=$ non significant 
Out of total 60 patients, highest percentage had history of smoking (61.7\%) followed by hypertension (60.0\%), diabetes mellitus (36.7\%), dyslipidaemia (23.3\%) and family history of IHD (21.7\%). The composite mean risk factors was $2.0 \pm 0.8$ ranging from (0-4). Analysis revealed that no statistically significant difference was found between two groups of patients $(p>0.05)$ in terms their history of risk factors except dyslipidaemia, however the history of smoking (63.3\%), diabetes mellitus (46.7\%) and dyslipidaemia were higher among group I patients, whereas hypertension (63.3\%), family history of IHD(30.0\%) were higher among group II (Table-II).

Among group I patients, highest percentage (80.0\%) had unstable angina and lowest non ST segment elevation myocardial infarction (20.0\%), whereas among group II patients, highest percentage had unstable angina (90.0\%) and lowest non ST elevation MI (10.0\%). However proportion of unstable angina was lower (80\%) and NSTEMI was higher (20\%) in group I compared to group II patients with UA (90\%) \& NSTEMI (10\%) respectively) (Table-III).

Among the group I, maximum patients (70.0\%) were found LM or LME CHD and found statistically highly significant (Sensitivity $=95 \%$, Specificity= $76 \%$, Positive predictive value $=70.0 \%$ and Negative predictive value $=97.0 \%$, double vessels disease were $16.7 \%$, single vessels were $13.3 \%$. 3 -vessels with LM or LME lesion were $30 \%$ and no patients were found in zero vessel or pure 3 -vessels disease, whereas in group-II patients, zero vessels were $43.4 \%$ and found statistically significant, double vessels were $26.7 \%$ and 3 -vessels as well as LM or LME were 3.3\% respectively and 3-vessels disease involvement were $13.3 \%$ (Table-IV).

\section{Table-II}

Distribution of risk factors of the study patients $(n=60)$.

\begin{tabular}{|c|c|c|c|c|c|c|c|}
\hline \multirow{3}{*}{ Risk factors } & \multicolumn{6}{|c|}{ Study Subject } & \multirow[t]{3}{*}{ p value } \\
\hline & \multicolumn{2}{|c|}{ Group I } & \multicolumn{2}{|c|}{ Group II } & \multicolumn{2}{|c|}{ Total } & \\
\hline & No. & $\overline{\%}$ & No. & $\%$ & No. & $\%$ & \\
\hline Smoking & 19 & 63.3 & 18 & 60.0 & 37 & 61.7 & $0.790^{\mathrm{NS}}$ \\
\hline Hypertension & 17 & 56.7 & 19 & 63.3 & 36 & 60.0 & $0.598^{\mathrm{NS}}$ \\
\hline Diabetes mellitus & 14 & 46.7 & 8 & 26.7 & 22 & 36.7 & $0.108^{\mathrm{NS}}$ \\
\hline Dyslipidaemia & 11 & 36.7 & 3 & 10.0 & 14 & 23.3 & $0.015^{\mathrm{S}}$ \\
\hline Family history of IHD & 4 & 13.3 & 9 & 30.0 & 13 & 21.7 & $0.117^{\mathrm{NS}}$ \\
\hline
\end{tabular}

Table-III

Distribution of patients by Acute Coronary Syndromes $(n=60)$.

\begin{tabular}{|c|c|c|c|c|c|c|c|}
\hline \multirow[t]{3}{*}{ Risk factors } & \multicolumn{6}{|c|}{ Study Subject } & \multirow[t]{3}{*}{$\mathrm{p}$ value } \\
\hline & \multicolumn{2}{|c|}{ Group I } & \multicolumn{2}{|c|}{ Group II } & \multicolumn{2}{|c|}{ Total } & \\
\hline & No. & $\%$ & No. & $\%$ & No. & $\%$ & \\
\hline Unstable angina & 24 & 80.0 & 27 & 90.0 & 51 & 85.0 & $* 0.236^{\mathrm{NS}}$ \\
\hline NSTEMI & 6 & 20.0 & 3 & 10.0 & 9 & 15.0 & \\
\hline Total & 30 & 100.0 & 30 & 100.0 & 60 & 100.0 & \\
\hline
\end{tabular}

* Fisher exact (1-tailed) NS= Non Significant $(\mathrm{P}>0.05) \mathrm{n}=$ sample size 
It was evident that among group I patients, $43.3 \%$ had stenotic lesion in LM and 26.67\% in LME CA, whereas had no stenotic lesion in LM and 3.33\% had LME CA lesion in group II patients (Table-V).

A positive correlation was found between the sum of ST-segment changes and the number of coronary artery lesion. A total amount of STsegment change of $<10 \mathrm{~mm}$ had $40 \%, 10-18 \mathrm{~mm}$ had $80.0 \%$ and more than $18 \mathrm{~mm}$ had $100 \% \mathrm{LM}$ or LME CA lesion. Only one patient of control with score more than $18 \mathrm{~mm}$ had LM or LME CA lesion (3.3\%) (Table-VI).

Table-IV

Distribution of number of coronary artery lesion by Coronary angiogram $(n=60)$.

\begin{tabular}{|c|c|c|c|c|c|c|c|}
\hline \multirow{3}{*}{$\begin{array}{l}\text { Number of diseased } \\
\text { Vessels }\end{array}$} & \multicolumn{6}{|c|}{ Study Subject } & \multirow[t]{3}{*}{$\mathrm{p}$ value } \\
\hline & \multicolumn{2}{|c|}{ Group I } & \multicolumn{2}{|c|}{ Group II } & \multicolumn{2}{|c|}{ Total } & \\
\hline & No. & $\%$ & No. & $\%$ & No. & $\%$ & \\
\hline $0 \mathrm{VD}$ & 0 & 0.0 & 13 & 43.4 & 13 & 21.7 & $0.000^{\mathrm{S}}$ \\
\hline $1 \mathrm{VD}$ & 4 & 13.3 & 8 & 26.7 & 12 & 20.0 & ns \\
\hline $2 \mathrm{VD}$ & 5 & 16.7 & 7 & 23.3 & 12 & 20.0 & $\mathrm{~ns}$ \\
\hline $3 \mathrm{VD}$ & 0 & 0.0 & 1 & 3.3 & 1 & 1.7 & $* \mathrm{~ns}$ \\
\hline$* *$ LM or LME & 21 & 70.0 & 1 & 3.3 & 22 & 36.6 & $0.000^{\mathrm{S}}$ \\
\hline Total: & 30 & 100 & 30 & 100 & 60 & 100 & \\
\hline 3 VD with LM or LME & 9 & 30 & 0 & 0.0 & 9 & 15 & $* 0.000^{\mathrm{S}}$ \\
\hline $3 \mathrm{~V}$ involvement & \multicolumn{2}{|c|}{$1 \mathrm{VD}(\mathrm{n}=4)$} & \multicolumn{2}{|c|}{$1 \mathrm{VD}(\mathrm{n}=8)$} & \multicolumn{2}{|c|}{ Total } & $\mathrm{p}$ value \\
\hline \multirow[t]{3}{*}{ (Non-significant lesion) } & \multicolumn{2}{|c|}{$2 \operatorname{VD}(n=5)$} & \multicolumn{2}{|c|}{$2 \operatorname{VD}(\mathrm{n}=8)$} & & & \\
\hline & \multicolumn{2}{|c|}{$\begin{array}{c}\mathrm{LM} / \mathrm{LME} \\
\quad(\mathrm{n}=21)\end{array}$} & \multicolumn{2}{|c|}{$\begin{array}{c}\text { Others } \\
(\mathrm{n}-14)\end{array}$} & & & \\
\hline & 9 & 30.0 & 4 & 13.33 & 11 & 18.33 & $\mathrm{Ns}$ \\
\hline
\end{tabular}

$\mathrm{p}$ value reached from chi square analysis, Sensitivity $=95 \%$, Specificity $=76 \%$

Positive predictive value $=70.0 \%$, Negative predictive value $=97.0 \%$, Accuracy $=83 \%$

$\mathrm{S}=$ significant $(\mathrm{p}<0.05) \mathrm{NS}=$ non significant $(\mathrm{p}>0.05) \mathrm{n}=$ sample size

Table-V

Distribution of pattern of coronary artery lesion in the study patients $(n=60)$.

\begin{tabular}{lccccccc}
\hline Lesion & \multicolumn{3}{c}{ Group I } & \multicolumn{3}{c}{ Study Subjects } & \multicolumn{3}{c}{ Total } & p value \\
& No. & $\%$ & No. & $\%$ & No. & $\%$ & \\
\hline$* * \mathrm{LM}$ & 13 & 43.3 & 0 & 0.0 & 13 & 21.7 & $0.000^{\mathrm{S}}$ \\
$* * \mathrm{LME}$ & 8 & 26.67 & 1 & 3.33 & 9 & 15 & $* 0.012^{\mathrm{S}}$ \\
$\mathrm{LAD}$ & 26 & 86.7 & 17 & 56.7 & 43 & 71.7 & $0.010^{\mathrm{S}}$ \\
$\mathrm{LCX}$ & 21 & 70.0 & 13 & 43.3 & 34 & 56.7 & $0.037^{\mathrm{S}}$ \\
RCA & 21 & 70.0 & 8 & 26.7 & 29 & 48.3 & $0.001^{\mathrm{S}}$ \\
\hline
\end{tabular}

$\mathrm{S}=$ significant $(\mathrm{P}<0.001), *$ Fisher exact $(1$-tailed $) *{ }^{*}$ Sensitivity $=95 \%,{ }^{* *}$ Specificity $=76 \%$

${ }^{* *}$ Positive predictive value $=70.0 \%{ }^{* *}$ Negative predictive value $=97.0 \%$ Accuracy $=83 \%$

$\mathrm{n}=$ sample size 
Table-VI

The "left main" Electrocardiographic pattern in relation to the sum of ST-Segment changes (score) and the number of severely narrowed coronary arteries $(n=60)$.

\begin{tabular}{|c|c|c|c|c|c|c|c|c|c|c|c|c|c|c|c|c|}
\hline \multirow{4}{*}{$\begin{array}{l}\text { Number of } \\
\text { disease vessels }\end{array}$} & \multicolumn{16}{|c|}{ Sum of ST changes $(\mathrm{mm})$} \\
\hline & \multicolumn{8}{|c|}{ Group I } & \multicolumn{8}{|c|}{ Group II } \\
\hline & \multicolumn{2}{|c|}{$\begin{array}{c}<10 \\
\mathrm{n}=10\end{array}$} & \multicolumn{2}{|c|}{$\begin{array}{l}10-18 \\
\mathrm{n}=15\end{array}$} & \multicolumn{2}{|c|}{$\begin{array}{l}>18 \\
\mathrm{n}=5\end{array}$} & \multicolumn{2}{|c|}{$\begin{array}{l}\text { Total } \\
\mathrm{n}=30\end{array}$} & \multicolumn{2}{|c|}{$\begin{array}{c}<10 \\
\mathrm{n}=25\end{array}$} & \multicolumn{2}{|c|}{$\begin{array}{c}10-18 \\
n=4\end{array}$} & \multicolumn{2}{|c|}{$\begin{array}{l}>18 \\
\mathrm{n}=1\end{array}$} & \multicolumn{2}{|c|}{$\begin{array}{l}\text { Total } \\
n=30\end{array}$} \\
\hline & No. & $\%$ & No. & $\%$ & No. & $\%$ & No. & $\%$ & No. & $\%$ & No. & $\%$ & No. & $\%$ & No. & $\%$ \\
\hline 0 & 0 & 0.0 & 0 & 0.0 & 0 & 0.0 & 0 & 0.0 & 12 & 48.0 & 1 & 25.0 & 0 & 0.0 & 13 & 43.3 \\
\hline 1 & 3 & 30.0 & 1 & 6.7 & 0 & 0.0 & 4 & 13.3 & 6 & 24.0 & 2 & 50.0 & 0 & 0.0 & 8 & 26.7 \\
\hline 2 & 3 & 30.0 & 2 & 13.3 & 0 & 0.0 & 5 & 16.7 & 6 & 24.0 & 1 & 25.0 & 0 & 0.0 & 7 & 23.3 \\
\hline 3 & 0 & 0.0 & 0 & 0.0 & 0 & 0.0 & 0 & 0.0 & 1 & 4.0 & 0 & 0.0 & 0 & 0.0 & 1 & 3.3 \\
\hline LM or ME & 4 & 40.0 & 12 & 80.0 & 5 & 100. & 21 & 70.0 & 0 & 0.0 & 0 & 0.0 & 1 & 100 & 1 & 3.3 \\
\hline
\end{tabular}

$\mathrm{n}=$ sample size

\section{Discussion:}

A large part of the myocardium of the left ventricle is perfused by the LMCA and its obstruction causes severe haemodynamic deterioration, frequently resulting in rapid fatality. ${ }^{5}$ As the amount of myocardium salvaged by revascularization, patients with greater risk may benefit from early revascularization. ECG is a less expensive, simple, non-invasive and can be a bedside test. This study was conducted to find-out the role of initial ECG changes in the prediction of culprit lesion in LM or LME CA by correlating with CAG.

In this study, the mean age of group I patients was $53.4 \pm 9.2$ years ranging from 40 to 75 years and group II patients was $48.8 \pm 10.0$ years ranging from 27 to 75 years. Analysis revealed that no statistically significant mean age difference was found between groups. It was found that among group I patients, highest percentage (43.3\%) had age group 45-54 years, $33.3 \%$ in age group 55-64 years, $13.4 \%$ in age group above 64 years. similar age incidence was reported in the past by Barrabe et al. ${ }^{6}$ Whereas among group II patients higher percentage (46.7\%) had age group 45-54 years, $26.7 \%$ in age group less than 45 years. The age range of patients of current study was 27-75 years. Similar pattern of age distribution were reported by Mujib in his study carried out in NICVD. ${ }^{7}$ Age is an un-modifiable strong independent risk factor for CHD, which increases markedly with the increase of age up to and/or above age 65 years. ${ }^{8}$

Out of 60 patients, $73.3 \%$ patients were male and $26.7 \%$ were female with male and female ratio $2.75: 1$. The number of female patients were less in almost all study. ${ }^{7,9}$ The overall lesser incidence of ACS among the female population in our country is probably due to protective effect of estrogen in premenopausal female \& lesser incidence of smoking in female. In this study, the mean age of the female patients was higher $(52.0 \pm 9.5$ years $)$ than the male patients ( $50.8 \pm 10.0$ years). The incidence of CAD in women increases after menopause and becomes equal to that of men by the age of 75 years. ${ }^{7}$

In this study, smoking was found as the commonest risk factor (61.7\%) followed by hypertension (60.0\%), diabetes mellitus (36.7\%), dyslipidaemia (23.3\%) and family history of IHD (21.7\%). Analysis revealed that no statistically significant difference was found between two groups of patients in terms their history of risk factors except dyslipidaemia, however the history of smoking, diabetes mellitus and dyslipidaemia were higher among group I patients, whereas hypertension, family history of IHD were higher among group II. Muttalib observed similar pattern of risk factors distribution. ${ }^{9}$ The investigator reported that $72 \%$ patients were smoker, $48 \%$ were diabetics, $34 \%$ were dyslipidaemic, $24 \%$ patients were hypertensive and $14 \%$ had positive family history of IHD. The proportion of smoking (81.1\%), also found statistically significant were higher among the male patients, whereas diabetes mellitus (43.8\%), hypertension (62.5\%) dyslipidaemia (25\%) and family history of IHD (25\%) were higher among the female patients but not statistically significant among the female patients compared to male patients. Smoking, diabetes mellitus, hypertension, hyperlipidemia and family history of IHD were considered as the major risk factors in several studies conducted in our country. The coronary lesions of cigarette smokers are more 
thrombogenic and less atherosclerotic. Mujib found smoking as highest number (81.8\%) followed by hypertension (58.9\%), diabetes mellitus (47\%) and family history $(40.4 \%){ }^{7}$

Regarding the clinical distribution of ACS patients, this study showed that among group I patients, highest percentage $(80.0 \%)$ had unstable angina and lowest non ST segment elevation myocardial infarction (20.0\%), whereas among group II patients, also highest percentage had unstable angina (90.0\%) and lowest non ST elevation MI $(10.0 \%)$. This may be due to the occurrence of higher mortality in NSTEMI in group I patients having LM or LMECA lesion before their arrival in the hospital. However proportion of unstable angina was lower (80\%) and NSTEMI was higher (20\%) in group -I compared to group-II patients (with UA-90\% \& NSTEMI-10\% respectively).

Analysis was found no statistically significant mean difference of pulse rate, systolic and diastolic blood pressure between two group of patients $(\mathrm{P}>0.05)$, whereas the mean blood pressure (systolic and diastolic) was high in group II patients compared to group I patients. In a similar type of study with STEMI associated with LMCA lesion by Mujib (2005) in NICVD showed opposite finding, significant number of patients were hemodynamically unstable (46\%) and developed heart failure. Alexander et al. showed similar finding, possibly myocardial damage more in their study population and less scope to revascularization. ${ }^{11}$ In present study, most of the patients were hemodynamically stable, predict major portion of myocardium still viable.

The present study showed that majority of study population had fair ejection fraction, reflect good left ventricular function. So revascularization may prolong survival. The mean percent of ejection fraction was $55.8 \pm 6.6$. It was $55.4 \pm 7.3$ in group I patients and $56.3 \pm 5.9$ in group II patients. Analysis showed that no statistically significant mean difference was found between two groups of patients, the mean percent of ejection fraction was low in group I patients compared to group II patients. It was found that the proportion of mean percent of ejection fraction less than 50 was higher in group I patients than group II patients. On the contrary, the mean percent of ejection fraction 5060 was higher in group II patients $(66.7 \%)$ than group I patients (50.0\%) and the mean percent of ejection fraction $>60$ was equal in both group (23.3\%).This finding predict group I patients were more critical

In this study, showed that among the group I patients having ST- segment depression with Twave inversion maximally in leads I, aVL, V4-V6 at rest angina, maximum patients $70.0 \%$ had LM or LME CHD and a statistically highly significant was found between two groups of patients $($ Sensitivity $=95 \%$, Specificity $=76 \%$, Positive predictive value $=70.0 \%$, Negative predictive value $=97.0 \%$ and Accuracy $=83 \%$ ), which revealed that ST- segment depression with T-wave inversion maximally in leads I, aVL, V4-V6 was a useful predictor of LM or LMECA lesion, double vessels disease were $16.7 \%$, single vessels were $13.3 \%$, 3 vessels with LM or LME lesion were $30 \%$ ) and no patients were found in zero vessel or pure 3-vessels disease, whereas in group-II patients having STsegment depression without T- wave inversion in lateral leads at rest angina, $43.4 \%$ had zero vessels disease and had found statistically significant, double vessels were $26.7 \%$ and 3 -vessels as well as LM or LME were 3.3\% respectively and 3-vessels disease involvement (non-significant lesion) were $13.3 \%$. Nikus et al. had found similar coronary artery lesion in their study with LM or LMECA lesion (76\%), 3VD (24\%) in group I patients whereas in group II had LM or LMECA lesion and 3 VD 8\% and $20 \%$ respectively. Similar pattern of coronary artery lesion distribution (LM-90\%) were reported by Anton et al. ${ }^{3}$

In present study, it was evident that among group I patients, $43.3 \%$ had stenotic lesion in LM and $26.67 \%$ in LME CA, whereas had no stenotic lesion in LM and 3.33\% had LME CA lesion in group II patients. This indicated that in group I patients, the risk of left main stenosis were 100 times higher than the group II patients. Analysis also revealed that predictive value of LM or LME lesion by ECG comparing with CAG, was highly sensitive (70.0\%), specific (92.0\%) and predictive accuracy was $81.0 \%$. Whereas the proportion of LAD lesion (86.7\%), LCX lesion (70.0\%), RCA lesion (70.0\%) were also higher in group I patients than in group II with LAD lesion (56.7\%), LCX lesion (43.3\%), RCA lesion (26.7\%) and found statistically highly significant. 
LM or LME CA disease associated with male gender, older age, with high ST-segment changes score, with increasing number of risk factors and more with diabetic \& dyslipidaemic patients. Finding related to male gender, increasing age, DM, dyslipidaemia and increasing number of risk factors were very much similar with different studies. ${ }^{10}$ Finding of ST- segment changes score also was similar to study carried out by Anton et al. ${ }^{3}$

\section{Conclusion}

The current study demonstrated a significant association between ST- segment depression with T-wave inversion maximally in the lateral leads I, avL,V4-V6 with high ST-segment changes score, male gender, older age, DM, dyslipidaemia and more number of risk factors $\left({ }^{3} 3\right)$ in ACS and critical LM or LMECA obstruction. Thus the present study showed that in patients with ACS, careful attention in the lateral leads I, aVL, V4-V6 with maximum ST- segment depression with T-wave inversion to predict the critical LM or LMECA obstruction is clinically important with respect to early diagnosis and selecting treatment strategy to reduce the mortality \& morbidity.

\section{Conflict of Interest - None.}

\section{References:}

1. WHO Fact sheet N310, updatedjune2011, http:// www.who. int/mediacentre/factsheets/fs310/en/ index.html.

2. Cutlip D, Baim DS. Management of left main coronary artery disease. 2003, May 17 last update. Available: hzz:/ www.utdol. Lom/ topic/ title in 15.

3. Anton PMG, Vos MA, Zwaan RMCD, Bar FWHM, Wallen HJJ. Value of the electrocardiogram in diagnosing the number of severely narrowed coronary arteries in rest angina. Am.J Cardiol 1993; 72: 999-1003.
4. Nikus K, Eskola M, Virtanen V, Vikman S, Nicmela K, Sclarovsky S. The ECG pattern of sudden obstruction of the Left Main or Equivalent coronary Artery. Circulation 2002; 106(19): 459.

5. Yamaji H, Iwasaki K, Kusachi S, Murakami T, Hirami R, Hina K. Prediction of Acute Left Main Coronary Artery Obstruction by 12- Lead Electrocardiography. $J$ Am Coll Cardiol 2001; 38: 1348-1354.

6. Barrabes JA, Figueras J, Moure C, Cortadellas J, Soler J. Prognostic significance of ST-segment depression in lateral leads $1, \mathrm{aVL}, \mathrm{V}_{5}$ and $\mathrm{V}_{6}$ on the admission electrocardiogram in patients with a first acute myocardial infarction without ST-segment elevation. $J$ Am Coll Cardiol 2000; 35: 1813-1819.

7. Mujib. Prediction of LMCA obstruction by 12-lead ECG in ACS (MD cardiology thesis).Dhaka: Bangabandhu Sheikh Mujib Medical University. 2005.

8. Falk E, Shah PK \& Fuster V. Coronary plaque disruption. Circulation 1995; 92: 657-671.

9. Muttalib. Correlation of residual ST-segment elevation after streptokinase therapy in acute ST-elevation myocardial infarction, with angiographic patency of infarction related coronary artery (MD cardiology thesis).Dhaka: Bangabandhu Sheikh Mujib Medical University. 2004.

10. Hubbard BL, Gibbons RJ, Lapeyre AC, Zinsmeister AR, Clements IP. Identification of severe coronary artery disease using simple clinical parameters. Arch intern Med 1992; 152(2): 302-312.

11. O'Rourke RA. Unstable angina and Non-ST-segment elevation myocardial infarction: clinical presentation diagnostic evaluation and medical management. In: Fuster V, Alexander RW \& O'Rourke RA. Eds. Hurst's The Heart. New York, USA: Mc Graw-Hill companies, Inc, 2004:1255-1259.

12. Austin WG, Edwards JE, Frye RL. A reporting system on patients evaluated for coronary artery disease; Report of the adhoc committee for grading coronary artery disease, Council on cardiovascular surgery, American Heart Association. Circulation 1975; 51: 5-40.

13. Bangladesh Cardiac Society \& National heart foundation of Bangladesh. Guideline for management of acute coronary syndrome (GL-ACS). 2004. 